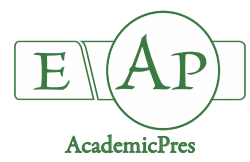

\title{
Evaluation of Genetic Stability and Effects of Plant Growth Regulators for in vitro Propagation of Underutilized Vitis amurensis 'Cheongsan'
}

\author{
Joon-Ho KWON ${ }^{1}$, Young-Sik PARK ${ }^{2}$, Si-Hong $\mathrm{KIM}^{3}$, Jae-Yun $\mathrm{HEO}^{1 *}$ \\ ${ }^{1}$ Gangnueng-Wonju National University, Department of Plant Science, Gangnueng 25457, \\ Korea; horticulture@naver.com;jyheo@gwnu.ac.kr ( ${ }^{*}$ correspondingauthor) \\ ${ }^{2}$ Gangwon Provincial Agricultural Research and Extension Services, Chuncheon 24226, Korea; yspark06@korea.kr \\ ${ }^{3}$ Kangwon National University, Department of Horticulture, Chuncheon 24341, Korea; tlghdek@kangwon.ac.kr
}

\begin{abstract}
Vitis amurensis 'Cheongsan' is a plant with high economic value in both medical and agricultural applications. However, its utilization has been restricted owing to difficulties encountered when applying traditional mass propagation methods, requiring instead application of in vitro propagation methods for their mass scale production. Hence, this study was conducted to find the optimal plant growth regulators for shoot multiplication and root induction during in vitro propagation. Among the three cytokinins used at multiple concentrations for culture initiation and shoot multiplication, the most positive response was found with MS medium containing $5.0 \mu \mathrm{M}$ 6-benzyladenine (BA), compared to more modest responses from other types of cytokinin, such as kinetin (KIN) and thidiazuron (TDZ). For root induction, medium supplemented with $\alpha$ naphthaleneacetic acid (NAA) produced a callus and inhibited shoot growth in explants, whereas indole-3-butyric acid (IBA) and indole-3-acetic acid (IAA) did not create any significant problems, but did display differences in root induction efficiencies. Generally, root induction responses with IBA were better that those with IAA. The maximum rooting rates were observed without callus formation and no shoot growth inhibition from explants grown on media supplemented with $0.67 \mu \mathrm{M}$ IBA. Further, inter-simple sequence repeat (ISSR) analyses revealed that micropropagated plantlets generated in medium supplemented with $5.0 \mu \mathrm{M} \mathrm{BA}$ and $0.67 \mu \mathrm{M}$ IBA did not lead to genetic variation. Therefore, the application of the in vitro propagation method developed in this study could be used on a commercial scale and will offer opportunities to strengthen the industrial use of $V$. amurensis 'Cheongsan'.
\end{abstract}

Keywords: auxin; cytokinin; ISSR marker; somaclonal variation

\section{Introduction}

Vitis amurensis belongs to the family Vitaceae. It has been regarded as an important medical crop and has long been used in various ethno-medical systems because it contains an abundance of resveratrol and anthocyanin, which have excellent anti-cancer, anti-oxidation, and antiinflammatory effects (Jang et al., 2007; Bak et al., 2016; Chen et al., 2018). In addition, it has received significant attention as a very useful breeding material, improving resistance to disease and the freezing tolerance of existing commercial grape varieties (Fennell, 2004; Chai et al., 2019; Fu et al., 2019). However, it has not been widely utilized for commercial purposes because of its substantially lower fruit quality and uneven productivity compared to commercial grape cultivars (Park et al., 2005a).

In order to complement these problems, some breeders have tried to improve the poor inherited characteristics of $V$. amurensis and enhance its direct use (Park et al., 2005b; Song et al., 2008). Finally, we developed $V$. amurensis 'Cheongsan' by crossing our strain with a Korean native $V$. amurensis possessing superior traits. It not only preserves all the important traits of $V$. amurensis, but also has much better fruit quality and very stable productivity (Park et al., 2017). Its value as a table grape and a wine grape in Korea is increasing because it has a distinguished fruit quality as an 
988

edible crop and properties beneficial to production of high quality wine (Heo et al., 2016). For this reason, the demand for $V$. amurensis 'Cheongsan' is increasing in Korea.

Grapevines are usually proliferated by stem cutting (Alley, 1980), but stems cut from $V$. amurensis do not produce roots easily (Guo et al., 1987). Hence, it is difficult to quickly supplying an adequate number of saplings to farmers using conventional methods of propagation, which prohibits wide commercial use of $V$. amurensis 'Cheongsan'. An alternative method for plants with these kinds of problems is an in vitro plant propagation method, which has been applied successfully to other systems (Hassan and Zayed, 2018). Other studies have demonstrated the merits of this approach, such as high propagation efficiencies produced through the application of plant growth regulators (PGRs) and avoidance of seasonal and space barriers for propagation work, compared to conventional propagation methods in many economically important crops (Lazo-Javalera et al., 2016; Mozafan et al., 2017; Toma, 2018). However, several researchers have indicated that the efficiency of in vitro propagation for Vitis spp. can differ significantly based on the interactions between the type and concentration of applied PGRs and the species or genotype of the crop (Aazami, 2010; Alzubi et al., 2012). In vitro propagation methods mainly consist of two steps: shoot multiplication and rooting. It is well known that shoot proliferation and rooting efficiency in Vitis spp. are affected by the type and concentration of cytokinin and auxin (Gray and Benton, 1991; Skiada et al., 2010). The efficiency of in vitro propagation can differ based on the genetic characteristics of the species, making it important to test their effects and to select the optimal PGR conditions.

Apart from this issue, some reports have shown that in vitro plant propagation methods could lead to somaclonal mutations. $V$. amurensis is a perennial crop and important genetic variations resulting from in vitro propagation may only be seen at maturity and fruiting. For this reason, early detection of genetic variations in in vitro raised plants is also important. However, examinations of morphological and phenological traits do not lead to precise determinations of clonal homogeneity. Hence, ISSR markers were chosen to screen the genetic stability of $V$. amurensis 'Cheongsan' in this study, as the assays are easily performed and highly reliable and the utilization of ISSR primers in evaluating genetic stability is well documented in several Vitis spp. (Nookaraju and Agrawal, 2012; Motha et al., 2017).

In order to assess the large-scale commercial use of $V$. amurensis 'Cheongsan', this study has investigated the optimal PGR composition for mass proliferation by in vitro culture and assessed the genetic stability of in vitro raised plants using ISSR markers.

\section{Materials and Methods}

\section{Culture establishment}

A total of 50 plants healthy greenhouse-grown 1-yearold potted $V$. amurensis 'Cheongsan' were used as source materials. For in vitro culture establishment, nodal explants with an axillary bud of a $2 \mathrm{~cm}$ long were used. They were collected from 3 to 6 node positions from the tip and downwards from young and actively growing shoots. The nodal segments were washed in running tap for $10 \mathrm{~min}$, and then surface sterilization was carried out under aseptic conditions. They were immersed in $70 \%$ ethanol for $1 \mathrm{~min}$, followed by $2 \%(\mathrm{w} / \mathrm{v}) \mathrm{NaOCl}$ for $10 \mathrm{~min}$, and then rinsed with sterile distilled water 5 times. For culture initiation, each nodal segment was placed in a Pyrex glass culture tube $(22 \mathrm{~mm} \times 200 \mathrm{~mm})$ containing $1 \times$ Murashige and Skoog (MS) medium supplemented with various cytokinins: 6benzyladenine (BA), kinetin (KIN) or thidiazuron (TDZ) at $1,2.5,5,7.5$, and $10 \mu \mathrm{M}$, supplemented with sucrose at 30 $\mathrm{g} / \mathrm{L}^{-1}$, and solidified with Difco-Bacto agar at $8 \mathrm{~g} / \mathrm{L}^{-1}$ separately. After 4 weeks of initial culture, induction of shoot organogenesis was investigated for each treatment. Each treatment had a total of 30 explants. Cultures were incubated at a temperature of $25 \pm 1{ }^{\circ} \mathrm{C}$ under 1,500-lux light intensity with $16 \mathrm{~h}$ of day light per photoperiod.

\section{Effects of plant growth regulators for shoot proliferation}

After 4 weeks of initial culture, micro cuttings from the first-generation in vitro shoots were sub cultured in culture vessels $(85 \mathrm{~mm} \times 110 \mathrm{~mm})$ with the same PGR composition except for KIN and incubated under the culture conditions described above to determine the optimum PGR conditions for multiple shoot proliferation. The number of shoots and nodes per explant were recorded along with the length of the main shoot after the 30 days of subculture. Each treatment for shoot multiplication consisted of four (4) replications each with six (6) explants.

\section{Effects of plant growth regulators for root induction and acclimatization}

For evaluation of PGR effects on root induction, elongated shoots derived from inoculated nodal segments were additionally sub cultured on the medium supplemented with $5 \mu \mathrm{M}$ BA until sufficient plant material was collected. When the experiment was ready, micro cuttings greater than $0.7 \mathrm{~cm}$ in length were prepared and moved to culture vessels supplied with different kinds of auxin or plant growth regulator free media. To determine optimum PGR conditions, a total of three types of auxin were tested: indole-3-acetic acid (IAA), indole-3-butyric acid (IBA) or $\alpha$-naphthaleneacetic acid (NAA) at $0.33,0.67$, $1.0,2.5$, and $5.0 \mu \mathrm{M}$. The conditions for the in vitro cultures were the same as those used for the shoot proliferation. The following data were assessed 30 days after the in vitro rooting treatments: rooting percentage, callusing percentage, total number of roots, main root length, and shoot length. Each treatment for root induction also consisted of four (4) replicates each with 6 explants.

Rooted plantlets were planted into a commercial substrate mix (Nongwoo Bio, Suwon, Korea) contained in plastic sundae cups with lids, placed in a Microclimate chamber at $25^{\circ} \mathrm{C}$, and hardened by gradually lowering the humidity over 4 weeks. Hardened-off plants were transferred into potting medium in $1 \mathrm{~L}$ plastic pots and maintained in the glasshouse of Gangneung-Wonju National University in Korea. 
Statistical analysis for shoot proliferation and root induction

Statistical analyses of the data were carried out with the SPSS 25.0 software program for Windows (SPSS Inc., Chicago, USA). An analysis of variance of treatment was performed to determine the effects of the treatments. When the treatment effects were statistically significantly $(\mathrm{P}<0.05)$, means were compared with Duncan's multiple range test.

Analysis of genetic stability by ISSR marker

A set of 10 in vitro raised plants derived from explants using 5.0 $\mu \mathrm{M}$ BA for shoot multiplication and $0.67 \mu \mathrm{M}$ IBA for root induction were randomly selected for evaluation of genetic stability by ISSR markers. Total genomic DNA was isolated from young leaf tissue of each in vitro derived plant by using the TaKaRa MiniBEST Plant Genomic DNA Extraction Kit (TaKaRa, Otsu, Japan) according to the manufacturer's instructions. A total of 15 ISSR primers were initially screened. Each reaction was prepared by using an Accupower premix (Bioneer, Daejeon, Korea) in a final volume of $20 \mu \mathrm{L}$ containing $10 \mathrm{pM}$ of each primer and $2 \mu \mathrm{L}$ of genomic DNA template.

PCR amplifications were performed in a Dice ${ }^{\circ}$ Touch (TaKaRa, Otsu, Japan) thermal cycler as follows: initial denaturing at $94^{\circ} \mathrm{C}$ for 5 min followed by 35 cycles of denaturation at $94^{\circ} \mathrm{C}$ for $30 \mathrm{sec}$, annealing at 48,50 , or 55 ${ }^{\circ} \mathrm{C}$ for $45 \mathrm{sec}$, amplification at $72{ }^{\circ} \mathrm{C}$ for $2 \mathrm{~min}$, and a final extension step of $7 \mathrm{~min}$ at $72{ }^{\circ} \mathrm{C}$. A $4-\mu \mathrm{L}$ aliquot of the reaction mixture was resolved by electrophoresis on a $1.5 \%$ agarose gel in 1X TAE buffer stained with GreenStarTM (Bioneer, Daejeon, Korea). Gels were visualized under UV light and photographed using a gel documentation system. Only consistently produced and well resolved fragments, in the size range of $100 \mathrm{bp}$ to $2,500 \mathrm{bp}$, were considered and scored as present or absent for ISSR markers in each sample. The genetic associations were assessed by calculating the Jaccard's similarity coefficient, the similarity matrix was subjected to the cluster analysis of unweighted pair group method with arithmetic averages (UPGMA), and a dendrogram was generated by using NTSYS-PC Ver. 2.1 software.

\section{Results and Discussion}

\section{Evaluation of hormonal effects for culture initiation}

The initial response of nodal segments incubated on different kind of cytokinin over a period of 30 days in culture is shown in Table 1. The sprouting of buds could be observed within two weeks of nodal segment incubation. The proportion of regeneration in nodal segments depended on the type and concentration of cytokinin used for the study, ranging from 46.7 100\% (Table 1). Culture medium without cytokinins failed to regenerate or to induce shoot and bud formation from nodal segments. However, nodal segments grown in media containing cytokinins were regenerated with callus formation after 10 days of culture and the generation of new axillary buds was frequently observed after 3 weeks of culture. Plants cultured in presence of BA and TDZ were found to have an acceptable regeneration rate and an adequate number of nodes and shoots. Among all the culture media examined, media containing BA produced the best response in terms of shoot and node formation. There was no significant difference in the regeneration rate among the different concentrations of BA supplement in the culture media, but number of shoots and nodes per nodal segment increased as BA concentration increased. Although the initial culture efficiency in media supplied with TDZ was slightly lower compared to that of BA, TDZ also had a positive effect on the number of axillary buds and shoots compared to cytokinin free medium. However, media treated with KIN had a much lower number of nodes and shoots, comparable to other media, with no difference between KIN and cytokinin free treatment. In Vitis spp. and other important woody crops, some researchers have also shown that KIN does not provide good results compared to BA and TDZ

Table 1. Effect of cytokinin type and concentration of plant growth regulators on culture establishment in Vitis amurensis 'Cheongsan'

\begin{tabular}{|c|c|c|c|c|}
\hline $\begin{array}{c}\text { Plant growth regulators / } \\
\text { Concentrations }\end{array}$ & $\begin{array}{c}\text { Bud induction rate / nodal } \\
\text { segment }(\%)\end{array}$ & $\begin{array}{c}\text { No. of shoots / nodal } \\
\text { segment }\end{array}$ & $\begin{array}{l}\text { No. of nodes / nodal } \\
\text { segment }\end{array}$ & $\begin{array}{l}\text { Length of main shoot } \\
\qquad(\mathrm{cm})\end{array}$ \\
\hline None & $60.0^{b}$ & $0.60^{d}$ & $2.27^{d}$ & $1.15^{\mathrm{c}}$ \\
\hline BA $1.0 \mu \mathrm{M}$ & $90.0^{a}$ & $1.07^{\mathrm{bc}}$ & $3.83^{\mathrm{ab}}$ & $2.03^{\mathrm{ab}}$ \\
\hline BA $2.5 \mu \mathrm{M}$ & $96.7^{a}$ & $1.17^{\mathrm{abc}}$ & $4.10^{\mathrm{a}}$ & $2.18^{\mathrm{ab}}$ \\
\hline BA $5.0 \mu \mathrm{M}$ & $93.3^{\mathrm{a}}$ & $1.27^{\mathrm{ab}}$ & $4.37^{\mathrm{a}}$ & $2.12^{\mathrm{ab}}$ \\
\hline BA $7.5 \mu \mathrm{M}$ & $96.7^{a}$ & $1.33^{\mathrm{ab}}$ & $4.50^{\mathrm{a}}$ & $1.87^{\mathrm{ab}}$ \\
\hline BA $10.0 \mu \mathrm{M}$ & $96.7^{a}$ & $1.40^{\mathrm{a}}$ & $4.63^{\mathrm{a}}$ & $1.77^{\mathrm{abc}}$ \\
\hline KIN $1.0 \mu \mathrm{M}$ & $50.0^{\mathrm{b}}$ & $0.50^{d}$ & $2.23^{\mathrm{d}}$ & $1.62^{b c}$ \\
\hline KIN $2.5 \mu \mathrm{M}$ & $53.3^{b}$ & $0.67^{\mathrm{d}}$ & $2.90^{\mathrm{bcd}}$ & $2.08^{\mathrm{ab}}$ \\
\hline KIN $5.0 \mu \mathrm{M}$ & $60.0^{\mathrm{b}}$ & $0.63^{d}$ & $2.73^{\mathrm{cd}}$ & $2.31^{\mathrm{ab}}$ \\
\hline KIN $7.5 \mu \mathrm{M}$ & $60.0^{\mathrm{b}}$ & $0.60^{d}$ & $2.53^{d}$ & $1.98^{\mathrm{ab}}$ \\
\hline KIN $10.0 \mu \mathrm{M}$ & $46.7^{b}$ & $0.47^{d}$ & $2.00^{\mathrm{d}}$ & $1.58^{\mathrm{bc}}$ \\
\hline TDZ $1.0 \mu \mathrm{M}$ & $86.7^{\mathrm{a}}$ & $0.93^{c}$ & $3.67^{\mathrm{abc}}$ & $1.94^{\mathrm{ab}}$ \\
\hline TDZ $2.5 \mu \mathrm{M}$ & $93.3^{a}$ & $1.07^{\mathrm{bc}}$ & $4.17^{\mathrm{a}}$ & $2.36^{\mathrm{ab}}$ \\
\hline TDZ $5.0 \mu \mathrm{M}$ & $100.0^{\mathrm{a}}$ & $1.17^{\mathrm{abc}}$ & $4.43^{a}$ & $2.48^{\mathrm{a}}$ \\
\hline TDZ $7.5 \mu \mathrm{M}$ & $93.3^{a}$ & $1.07^{\mathrm{bc}}$ & $4.03^{\mathrm{a}}$ & $2.20^{\mathrm{ab}}$ \\
\hline TDZ $10.0 \mu \mathrm{M}$ & $90.0^{\mathrm{a}}$ & $1.03^{\mathrm{bc}}$ & $4.10^{\mathrm{a}}$ & $2.29^{\mathrm{ab}}$ \\
\hline
\end{tabular}

Note: Means followed by the same letter within each column are not significantly different at P 0.05 . 
990

(Alizadeh et al., 2012; Jamwal et al., 2013). Hence, the application of KIN at the lowest concentration used for this study appeared to have no positive effect for regeneration or for new bud induction in $V$. amurensis 'Cheongsan'.

Evaluation of hormonal effects for shoot proliferation

$\mathrm{BA}$ and TDZ were chosen for further study in order to determine the optimal cytokinin and most effective concentration for shoot multiplication, as treatment with these agents had positive effects during the initial stages of culture. Subculture responses of explants prepared from the initial cultures also differed with the type and concentration of cytokinin (Table 2). Overall, media containing BA had better subculture responses, but the difference between $\mathrm{BA}$ and TDZ was small. From all bud-induced explants, at least one shoot had emerged with small callus formation soon after bud break, but the degree of formation of additional shoots and nodes was significantly different depending on the type and concentration of cytokinin examined. However, media supplemented with either cytokinin produced more shoots, nodes, regardless of concentration, compared to cytokinin-free media; thus, shoot, and node induction in the subculture process appeared to be a function of the cytokinin.

TDZ had a very positive effect on main shoot development and no negative symptoms regarding the shoot and node formation were observed. Subculture responses, determined by the shoot induction in media containing TDZ, were measured from 83.3 to $91.7 \%$ and the number of shoots, the number of nodes, and the length of the main shoot ranged from 1.08 to 1.58 , from 4.08 to 5.42 , and from 1.39 to 1.74 , respectively. Other criteria tended to respond better as the concentration of TDZ increased to $7.5 \mu \mathrm{M}$, then decreased at higher concentrations. It has been frequently reported that TDZ applications for shoot induction cause fascination and inhibition of shoot elongation in Vitis spp. as a side effect of high cytokinin activity with TDZ, but we could not investigate these types of problems. However, others have reported positive effects of TDZ on multiple shoot formation, without any negative phenomenon, in different wild plant species (Sivanesan et al., 2011; Grabkowska et al., 2014; Siddique et al., 2015). Hence, these results suggest that application of TDZ for in vitro propagation can also be useful in $V$. amurensis 'Cheongsan', although TDZ and BA provided similar positive effects.

Subculture responses in media containing BA were good during the initial culture period and remained very stable at all concentrations. In addition, the number of shoots and nodes improved even at relatively low concentrations. Among all hormonal conditions examined for this study, the highest number of shoot and nodes per explant were observed with media containing $5.0 \mu \mathrm{M} \mathrm{BA}$, which produced 1.96 shoots and 6.42 nodes per explant. These values were 1.24- and 1.18-fold greater than TDZ at 7.5 $\mu \mathrm{M}$. The optimal type and concentration of cytokinin for in vitro propagation varied considerably among different plant species (Fan et al., 2017; Kefayeti et al., 2019), but earlier work has reported the positive stimulating effects of BA on multiple shoot formation for several plants (Modgil and Thakur, 2015; Khatun, 2017). In Vitis spp., the optimum BA concentration for shoot multiplication was found to range from 2.22 to $11.1 \mu \mathrm{M}$, while the number of shoots and nodes decreased in explants at supra-optimal BA concentrations, resulting in complete suppression of bud break or more compact callus formations that inhibited shoot growth (Mozafari et al., 2017; Yildirim and Ozdemir, 2018). Other studies have reported that of the five BA concentrations examined, $5.0 \mu \mathrm{M}$ BA showed the best results in the number of shoots and nodes per explant, while concentrations higher than $5.0 \mu \mathrm{M}$ BA caused these numbers to decrease. More importantly, the initial culture efficiency at $5.0 \mu \mathrm{M}$ BA was very acceptable and the shoots generated from these initial cultures, fed into a subculture application using 5.0 $\mu \mathrm{M} \mathrm{BA}$, had more uniform size and good leaf appearance with a green color. These results strongly indicate that $5.0 \mu \mathrm{M} \mathrm{BA}$ is appropriate for sustainable in vitro propagation of $V$. amurensis 'Cheongsan'.

Table 2. Effect of cytokinin type and concentration of plant growth regulators on shoot multiplication in Vitis amurensis 'Cheongsan'

\begin{tabular}{|c|c|c|c|c|}
\hline $\begin{array}{l}\text { Plant growth regulators / } \\
\text { Concentrations }\end{array}$ & $\begin{array}{l}\text { Culture response } \\
\text { (\%) }\end{array}$ & $\begin{array}{l}\text { No. of shoots/explant } \\
\text { inoculated (no.) }\end{array}$ & $\begin{array}{l}\text { No. of nodes / explant } \\
\text { inoculated (no.) }\end{array}$ & $\begin{array}{l}\text { Length of main shoot } \\
\qquad(\mathrm{cm})\end{array}$ \\
\hline None & $33.3^{b}$ & $0.38^{\mathrm{e}}$ & $1.28^{c}$ & $0.47^{b}$ \\
\hline BA $1 \mu \mathrm{M}$ & $95.8^{a}$ & $1.38^{\mathrm{abcd}}$ & $4.75^{\mathrm{ab}}$ & $1.26^{\mathrm{ab}}$ \\
\hline BA $2.5 \mu \mathrm{M}$ & $87.5^{a}$ & $1.54^{\mathrm{abcd}}$ & $5.46^{\mathrm{ab}}$ & $1.33^{\mathrm{ab}}$ \\
\hline $\mathrm{BA} 5 \mu \mathrm{M}$ & $91.7^{\mathrm{a}}$ & $1.96^{\mathrm{a}}$ & $6.42^{\mathrm{a}}$ & $1.57^{\mathrm{ab}}$ \\
\hline BA $7.5 \mu \mathrm{M}$ & $87.5^{\mathrm{a}}$ & $1.79^{\mathrm{abc}}$ & $5.96^{\mathrm{ab}}$ & $1.31^{\mathrm{ab}}$ \\
\hline BA $10 \mu \mathrm{M}$ & $83.3^{\mathrm{a}}$ & $1.88^{\mathrm{ab}}$ & $6.00^{\mathrm{ab}}$ & $1.20^{\mathrm{ab}}$ \\
\hline $\mathrm{TDZ} 1 \mu \mathrm{M}$ & $91.7^{\mathrm{a}}$ & $1.08^{d}$ & $4.08^{\mathrm{b}}$ & $1.45^{\mathrm{ab}}$ \\
\hline TDZ $2.5 \mu \mathrm{M}$ & $83.3^{a}$ & $1.17^{\mathrm{bc}}$ & $4.42^{\mathrm{ab}}$ & $1.58^{\mathrm{ab}}$ \\
\hline $\mathrm{TDZ} 5 \mu \mathrm{M}$ & $83.3^{a}$ & $1.29^{b c}$ & $4.92^{\mathrm{ab}}$ & $1.4^{\text {ab }}$ \\
\hline TDZ $7.5 \mu \mathrm{M}$ & $87.5^{\mathrm{a}}$ & $1.58^{\mathrm{abcd}}$ & $5.42^{\mathrm{ab}}$ & $1.74^{a}$ \\
\hline TDZ $10 \mu \mathrm{M}$ & $87.5^{\mathrm{a}}$ & $1.42^{\mathrm{abcd}}$ & $5.04^{\mathrm{ab}}$ & $1.50^{\mathrm{ab}}$ \\
\hline
\end{tabular}


Evaluation of hormonal effects for root induction

Differential responses were observed for root induction in explants as a function of the type and concentration of auxins (Table 3). A lower rate of root induction was observed when explants produced from $5.0 \mu \mathrm{M}$ BA were cultured on media without the application of plant growth regulators. Under non-optimal conditions, the lower part of the explants became black or produced a callus within two weeks and root growth stopped after $1 \mathrm{~cm}$ of growth. Overall, IBA was more effective than IAA and NAA, as it had a higher rooting rate percentage and a greater number of roots. Among the three auxins examined at multiple concentrations, $0.67 \mu \mathrm{M}$ IBA was the most effective hormone, as it showed the maximum percent rooting $(87.5 \%)$ and had the second highest number of roots produced (3.25) without any callus formation. At the same level of hormone, IAA and NAA produced 2.21 roots at a rooting rate of $70.8 \%$ and 2.46 roots at a rooting rate of $66.7 \%$, respectively (Table 1 ). In this experiment, the root number was enhanced by treatment with 1 to $5 \mu \mathrm{M}$ NAA, but these treatments induced callus formation. Moreover, shoot growth was significantly inhibited at higher concentrations of NAA compared to other types of auxin. In contrast, IAA did not lead to the formation of callus or notable growth inhibition at lower concentrations, but most important criteria, including the rooting rate, were lower than those with IBA.

Several researchers have demonstrated the rooting of explants is strongly influenced in many important woody plants by the type of auxin used (Oliveira et al., 2016; Rajoriya et al., 2018). It has been well established that the optimal type of auxin hormone for root induction differs with species or genotypes. While positive results have been reported with NAA applications for root induction in several species (Azhar et al., 2018; Naaz et al., 2019), some studies have also reported toxicity and callus formation problems resulting in unsuccessful acclimatization of plantlets (De Klerk et al., 1997; Alosaimi et al., 2018). In this study, side effects, like callus formation and non-shoot induction, were also observed in $V$. amurensis 'Cheongsan' following the application of NAA and these effects became worse at higher NAA concentrations. Our negative findings concerning NAA applications to the process of root induction are similar with previous reports and might indicate a genetic property, such as sensitivity to NAA toxicity in $V$. amurensis 'Cheongsan'. In addition, IAA applications were also less effective for root induction in $V$. amurensis 'Cheongsan' compared to IBA applications. This result can be explained by the physical characteristics of IAA, which can breakdown with light exposure and in the solid agar plate media conditions used in this study, compared to IBA (Dunlap and Robacker, 1988), or the reduced interaction effect between the remaining $B A$, used for the shoot multiplication process, and the IAA, used for root induction, compared to IBA. Although further investigation is needed to provide a clear explanation of these observations, our results indicate that application of IBA might be more effective for the in vitro propagation of $V$. amurensis 'Cheongsan' in terms of stability, persistence, and toxicity protection in media when utilizing our protocol.

Good physiological conditions are absolutely critical for successful acclimatization of plantlets. In a survival test using 42 plantlets produced with $5.0 \mu \mathrm{M}$ BA for shoot induction and $0.67 \mu \mathrm{M}$ IBA during acclimatization (data not published), only 2 plantlets died; thus, no survival problems were found. These results suggest that the application of $5.0 \mu \mathrm{M} \mathrm{BA}$ and $0.67 \mu \mathrm{M}$ IBA during shoot multiplication and root induction is very effective for in vitro propagation of $V$. amurensis 'Cheongsan'.

Table 3. Effect of auxin type and concentration of plant growth regulators on root induction in Vitis amurensis 'Cheongsan'

\begin{tabular}{|c|c|c|c|c|c|}
\hline $\begin{array}{l}\text { Plant growth regulators / } \\
\text { Concentrations }\end{array}$ & $\begin{array}{c}\% \\
\text { of rooting }\end{array}$ & $\begin{array}{c}\% \\
\text { of callusing }\end{array}$ & $\begin{array}{c}\text { Root } \\
\text { number }\end{array}$ & $\begin{array}{l}\text { Root length } \\
(\mathrm{cm})\end{array}$ & $\begin{array}{l}\text { Shoot length } \\
(\mathrm{cm})\end{array}$ \\
\hline None & $41.7^{b}$ & $0^{d}$ & $0.42^{\mathrm{c}}$ & $0.73^{c}$ & $0.55^{\mathrm{c}}$ \\
\hline IAA $0.33 \mu \mathrm{M}$ & $75.0^{2}$ & $0^{d}$ & $2.04^{\mathrm{bcd}}$ & $1.34^{\mathrm{a}}$ & $1.22^{\mathrm{abcd}}$ \\
\hline IAA $0.67 \mu \mathrm{M}$ & $70.8^{\mathrm{ab}}$ & $0^{\mathrm{d}}$ & $2.21^{\mathrm{bcd}}$ & $1.18^{\mathrm{abc}}$ & $1.36^{\mathrm{abcd}}$ \\
\hline IAA $1.0 \mu \mathrm{M}$ & $75.0^{a}$ & $0^{\mathrm{d}}$ & $2.50^{\mathrm{abcd}}$ & $1.00^{\mathrm{abc}}$ & $1.26^{\mathrm{abcd}}$ \\
\hline IAA $2.5 \mu \mathrm{M}$ & $70.8^{\mathrm{ab}}$ & $0^{\mathrm{d}}$ & $2.79^{\mathrm{abcd}}$ & $1.08^{\mathrm{abc}}$ & $1.48^{\mathrm{abc}}$ \\
\hline IAA $5.0 \mu \mathrm{M}$ & $66.7^{\mathrm{ab}}$ & $0^{d}$ & $2.54^{\mathrm{abcd}}$ & $0.90^{\mathrm{abc}}$ & $1.31^{\mathrm{abcd}}$ \\
\hline IBA $0.33 \mu \mathrm{M}$ & $83.3^{\mathrm{a}}$ & $0^{d}$ & $2.29^{\mathrm{bcd}}$ & $1.05^{\mathrm{abc}}$ & $1.46^{\mathrm{abcd}}$ \\
\hline IBA $0.67 \mu \mathrm{M}$ & $87.5^{a}$ & $0^{\mathrm{d}}$ & $3.25^{\mathrm{ab}}$ & $1.20^{\mathrm{abc}}$ & $1.54^{\mathrm{ab}}$ \\
\hline IBA $1.0 \mu \mathrm{M}$ & $79.2^{\mathrm{a}}$ & $12.5^{\mathrm{cd}}$ & $2.96^{\mathrm{abcd}}$ & $1.28^{\mathrm{ab}}$ & $1.65^{\mathrm{a}}$ \\
\hline IBA $2.5 \mu \mathrm{M}$ & $70.8^{\mathrm{ab}}$ & $8.3^{\mathrm{cd}}$ & $2.45^{\mathrm{abcd}}$ & $1.08^{\mathrm{abc}}$ & $1.25^{\mathrm{abcd}}$ \\
\hline IBA $5.0 \mu \mathrm{M}$ & $66.7^{\mathrm{ab}}$ & $20.8^{c}$ & $1.92^{\mathrm{cd}}$ & $0.73^{c}$ & $0.98^{\text {cde }}$ \\
\hline NAA $0.33 \mu \mathrm{M}$ & $62.5^{\mathrm{ab}}$ & $54.1^{b}$ & $1.83^{\mathrm{d}}$ & $0.81^{b c}$ & $0.65^{\mathrm{e}}$ \\
\hline NAA $0.67 \mu \mathrm{M}$ & $66.7^{\mathrm{ab}}$ & $58.3^{\mathrm{ab}}$ & $2.46^{\mathrm{bccd}}$ & $1.02^{\mathrm{abc}}$ & $0.91^{\mathrm{de}}$ \\
\hline NAA $1.0 \mu \mathrm{M}$ & $70.8^{\mathrm{ab}}$ & $70.8^{\mathrm{ab}}$ & $3.00^{\mathrm{abcd}}$ & $1.18^{\mathrm{abc}}$ & $1.06^{\mathrm{bcd}}$ \\
\hline NAA $2.5 \mu \mathrm{M}$ & $70.8^{\mathrm{ab}}$ & $70.8^{\mathrm{ab}}$ & $3.13^{\text {abc }}$ & $0.92^{2 \mathrm{bc}}$ & $0.00^{f}$ \\
\hline NAA $5.0 \mu \mathrm{M}$ & $79.2^{\mathrm{a}}$ & $79.2^{\mathrm{a}}$ & $3.67^{a}$ & $1.04^{\mathrm{abc}}$ & $0.00^{f}$ \\
\hline
\end{tabular}


Table 4. List of ISSR primers used for this study and number of band classes generated

\begin{tabular}{cccccc}
\hline $\begin{array}{c}\text { ISSR } \\
\text { primer }\end{array}$ & $\begin{array}{c}\text { Annealing temperature } \\
\left({ }^{\circ} \mathrm{C}\right)\end{array}$ & $\begin{array}{c}\text { No. of distinct band } \\
\text { classes }\end{array}$ & $\begin{array}{c}\text { No. of } \\
\text { distinct band }\end{array}$ & $\begin{array}{c}\text { Total number of bands } \\
\text { amplified }\end{array}$ & $\begin{array}{c}\% \\
\text { of similarity }\end{array}$ \\
\hline UBC 808 & 50 & 9 & 9 & 99 & 100 \\
UBC 823 & 50 & 4 & 4 & 64 & 100 \\
UBC 825 & 55 & 6 & 6 & 66 & 100 \\
UBC 836 & 50 & 8 & 8 & 88 & 100 \\
UBC 840 & 50 & 8 & 6 & 88 & 100 \\
UBC 857 & 55 & 6 & 66 & 100 \\
UBC 864 & 48 & 7 & 7 & 110 & 100 \\
UBC 873 & 50 & 10 & 10 & 110 & 100 \\
UBC 880 & 50 & 10 & 11 & 121 & 100 \\
UBC 885 & 50 & 11 & 11 & 121 & 100 \\
UBC 891 & 55 & 11 & & 100 \\
\hline
\end{tabular}

Analysis of genetic stability reported by ISSR marker

Genetic stability was assessed among 10 in vitro raised plants and compared with their mother plant. A total of 15 ISSR primers were tested, out of which 11 ISSR primers were successful in amplifying the genomic DNA and giving reproducible bands, producing 90 distinct and scorable bands. The number of scorable bands varied from 100 to $2,000 \mathrm{bp}$ with an average of 8.2 bands per primer. All the primers generated monomorphic bands across all the in vitro raised plants and the mother plant shown in Fig. 1, indicating that in vitro raised $V$. amurensis 'Cheongsan' preserved genetic stability without any notable morphological differences. Our result is consistent with other findings showing no genetic variations from in vitro raised plantlets of several species of plants (Purohit et al., 2016; Jena et al., 2018; Behera et al., 2019).

The presence or absence of variation during in vitro propagation depends on the source of the explants and the method of regeneration (Goto et al., 1998). Among the various in vitro propagation methods, the utilization of nodal segments is most widely used (Rani et al., 1995) because of its simplicity as an in vitro propagation system and its high multiplication efficiency. More importantly, plants established from adventitious buds around the axillary buds, or from other well-developed meristematic tissue of the nodal segment, had the lowest risk of genetic variation (Martins et al., 2004; Joshi and Dhawan, 2007). However, it has been reported that plants derived from these tissues are not always genetically identical, as the use of sub- and supra-optimal levels of plant growth hormones, especially synthetic ones, can also cause somaclonal variation (Martin and Pachathundkandi, 2006). These results indicate that the hormonal conditions applied in this study for shoot multiplication and root induction were also optimal for the maintenance of genetic stability in $V$. amurensis 'Cheongsan' during in vitro culture.

\section{Conclusions}

In vitro plant propagation is important to the effective production of plants that are genetically identical to the mother plant. In this study, we found that the application of $5.0 \mu \mathrm{M} \mathrm{BA}$ and $0.67 \mu \mathrm{M}$ IBA can be highly effective for $V$. amurensis 'Cheongsan' plantlet production, generating a
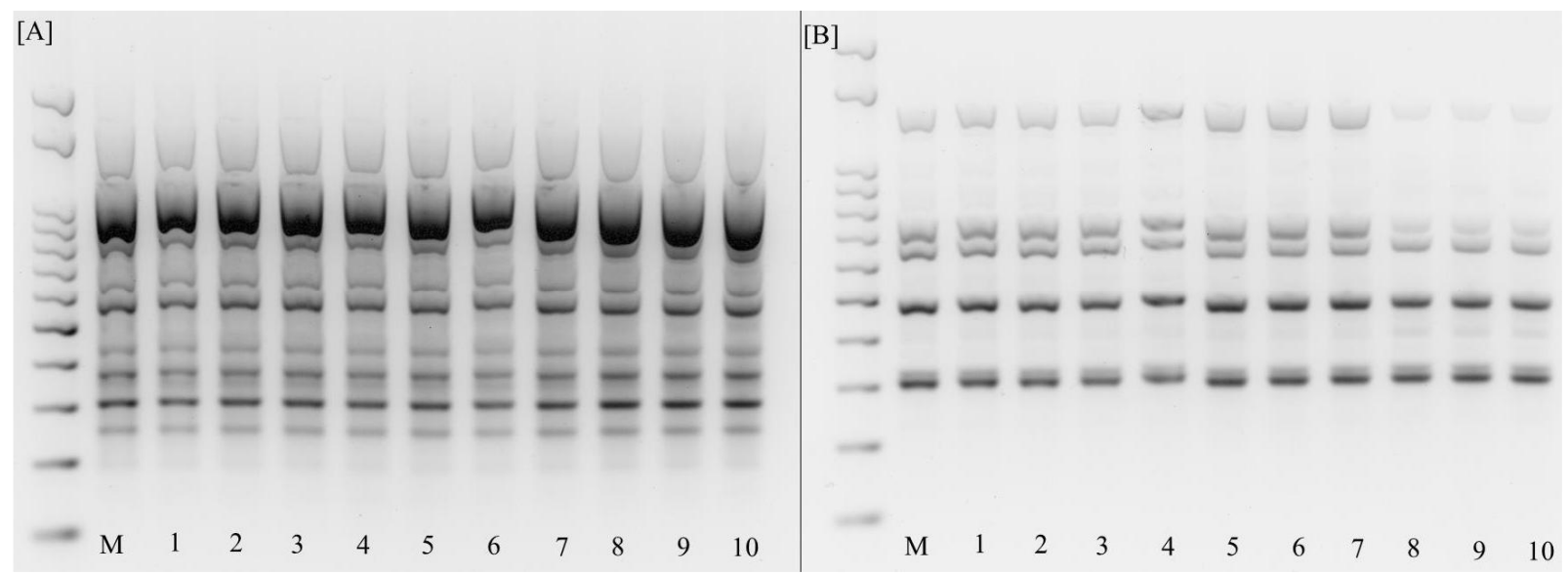

Fig. 1. ISSR profiles of in vitro raised Vitis amurensis 'Cheongsan' leaf DNA samples with UBC 808[A] and 825[B]. M: mother plant, 1-10: In vitro raised plants 
greater number of shoots and roots compared to hormone free growth, or compared to the application of other kinds of hormones. Furthermore, no somaclonal variation was found among in vitro raised plants using $5.0 \mu \mathrm{M} B A$ for the shoot induction step and $0.67 \mu \mathrm{M}$ IBA for the root induction step. Hence, in vitro plant propagation by our protocol can be successfully employed to ensure genetic stability in the commercial multiplication of $V$. amurensis 'Cheongsan'.

\section{Acknowledgements}

This work was supported by the National Research Foundation of Korea (NRF) grant funded by the Korea government (MSIT) (No. 2017R1C1B2008589).

\section{Conflict of Interest}

The authors declare that there are no conflicts of interest related to this article.

\section{References}

Aazami MA (2010). Effect of some growth regulators on "in vitro" culture of two Vitis vinifera L. cultivars. Romanian Biotechnological Letters 15:5229-5232.

AlleyCJ (1980). Propagation of grapevines. California Agriculture 34:29-30.

Alosaimi AA, Tripepi RR, Love SL (2018). Micropropagation of Epilobium canum garretti (Firechalice) by axillary shoot culture. HortScience 53(1):62-66.

Alzubi H, Yepes LM, Fuchs M (2012). Enhanced micropropagation and establishment of grapevine rootstock genotypes. International Journal of Plant Developmental Biology6(1):9-14.

AzharSZA, Ghani KA, YusufNA (2018).In vitro induction of adventitious root from shoot bud of Boesen bergia rotunda (Zingiberaceae): Effect of plant growth regulators. Science International (Lahore) 30(1):147-151.

Bak MJ, Truong VL, Ko SY, Nguyen XNG, Ingkasupart P, Jun M, ... Jeong WS (2016). Antioxidant and hepatoprotective effects of procyanidins from wild grape (Vitis amurensis) seeds in ethanol-induced cells and rats. International Journal of Molecular Sciences 17(5):758.

Behera S, Kar SK, Rout KK, Barik DP, Panda PC, Naik SK (2019). Assessment of genetic and biochemical fidelity of field-established Hedychium coronarium J. Koenig regenerated from axenic cotyledonary node on meta-topolin supplemented medium. Industrial Crops and Products 134:206-215.

Chai F, Liu W, Xiang Y, Meng X, Sun X, Cheng C, ... Li S (2019). Comparative metabolic profiling of Vitis amurensis and Vitis vinifera during cold acclimation. Horticulture Research 6(1):8.

Chen Q, Diao L, Song H, Zhu X (2018). Vitis amurensis Rupr: A review of chemistry and pharmacology. Phytomedicine 49:111-122.

De Klerk GJ, Ter Brugge J, Marinova S (1997). Effectiveness of indoleacetic acid, indolebutyric acid and naphthaleneacetic acid during adventitious root formation in vitro in Malus 'eJork 9'. Plant Cell, Tissue and Organ Culture $49(1): 39-44$.
De Oliveira ML, Thomson JG, Stover E (2016). High-efficiency propagation of mature 'Washington Navel' orange and juvenile 'Carrizo' citrange using axillary shoot proliferation. HortTechnology 26(3):278286.

Dunlap JR, Robacker K (1988). Light and nutrient salts interact to destroy IAA in tissue culture media. Plant Physiology 88(2):379-382.

Fan S, Jian D, Wei X, Chen J, Beeson RC, Zhou Z, Wang X (2017). Micropropagation of blueberry 'Bluejay' and 'Pink Lemonade' through in vitro shoot culture. Scientia Horticulturae 226:227-284.

Fennell A (2004). Freezing tolerance and injury in grapevines. Journal of Crop Improvement 10(1-2):201-235.

Fu P, Tian Q, Lai G, Li R, Song S, Lu J (2019). Cgr1, a ripe rot resistance QTL in Vitis amurensis 'Shuang Hong' grapevine. Horticulture Research 6(1):67.

Goto S, Thakur RC, Ishii K (1998). Determination of genetic stability in long-term micropropagated shoots of Pinus thunbergii Parl. using RAPD markers. Plant Cell Reports 18(3-4):193-197.

Grabkowska R, Sitarek P, Wysokinska H (2014). Influence of thidiazuron (TDZ) pretreatment of shoot tips on shoot multiplication and ex vitro acclimatization of Harpagophytum procumbens. Acta Physiologiae Plantarum 36(7):1661-1672.

Gray DJ, Benton CM (1991). In vitro micropropagation and plant establishment of muscadine grape cultivars (Vitis rotundifolia). Plant Cell, Tissue and Organ Culture 27(1):7-14.

GuoXW,Fu WH, Wang GJ (1987). Studies on cold hardiness of grapevine roots. Vitis 26:161-171.

Hassan SAM, Zayed NS (2018) Factor controlling micropropagation of fruit trees: a review. Science International 6(1):1-10.

Heo JY, Um NY, Jeong ST, Park YS (2016). Quality characteristics of red wine from 'Cheongsan' (Vitis amurensis) grape cultivar. The journal of the Korean Society of International Agriculture 28:237-242.

Jamwal M, Singh B, Sharma N, Kumar R, Sharma A, Sharma RM, ... Parmar AM (2013). In vitro regeneration of grape (Vitis vinifera $\mathrm{L}$.) cv. 'Perlette'. World Journal of Agricultural Sciences 9(2):161-166.

Jang MH, Piao XI, Kim HY, Cho EJ, Baek SH, Kwon SW, Park JH (2007). Resveratrol oligomers from Vitis amurensis attenuate $\beta$-amyloidinduced oxidative stress in PC12 cell. Biological and Pharmaceutical Bulletin 30(6):1130-1134.

Jena S, Ray A, Sahoo A, Sahoo S, Kar B, Panda C, Nayak S (2018). Highfrequency clonal propagation of Curcuma angustifolia ensuring genetic fidelity of micropropagated plants. Plant Cell, Tissue and Organ Culture 135(3):473-486.

Joshi P, Dhawan V (2007). Assessment of genetic fidelity of micropropagated Swertia chirayita plantlets by ISSR marker assay. Biologia Plantarum 51(1):22-26.

Kefayeti S, Kafkas E, Ercisli S (2019). Micropropagation of 'Chester thornless' blackberry cultivar using axillary bud explants. Notulae Botanicae Horti Agrobotanici Cluj-Napoca 47(1):162-168.

Khatun F, Hoque ME, Huq H, Adil M, Ashraf-Uz-Zaman K, Rabin MH (2017). Effect of BAP and IBA on in vitro regeneration of local banana variety of Sabri. Biotechnology Journal International 18(1):1-10. 
994

Lazo-Javalera MF, Troncoso-Rojas R, Tiznado-Hernandez ME, MartinezTellez MA, Vargas-Arispuro I, Islas-Osuna MA, Rivera-Dominguez M (2016). Surface disinfection procedure and in vitro regeneration of grapevine (Vitis vinifera L.) axillary buds. SpringerPlus 5(1):453.

Martins M, Sarmento D, Oliveira MM (2014). Genetic stability of micropropagated almond plantlets, as assessed by RAPD and ISSR markers. Plant Cell Reports 23(7):492-496.

Modgil M, Thakur M (2015). In vitro culture of clonal rootstocks of apple for their commercial exploitation. In: VI International Symposium on Production and Establishment of Micropropagated Plants 1155:331336.

Motha K, Singh SK, Singh R, Ram C, Srivastav M, Verma MK, ... Dev R (2017). Comparative in vitro propagation of stress tolerant grape (Vitis spp.) rootstocks and assessment of clonal fidelity of plantlets. The Horticultural Society of India 74(3):317-325.

Mozafan AA, Ghoraishi O, Ghaderi N, Javadi T (2017). Micropropagation of grape cultivars (Vitis vinifera L.) on different basal media supplemented with benzyl adenine. Agriculturae Conspectus Scientificus 81(3):123-129.

Naaz A, Hussain SA, Anis M, Alatar AA (2019). Meta-topolin improved micropropagation in Syzygium cumini and acclimatization to ex vitro conditions. Biologia Plantarum 63(1):174182.

Nookaraju A, Agrawal DC (2012). Genetic homogeneity of in vitro raised plants of grapevine cv. 'Crimson Seedless' revealed by ISSR and microsatellite markers. South African Journal of Botany 78:302-306.

Park YS, Heo JY, Kim IJ, Heo SJ, Kim KH, Jeong BC, Park SM (2005a). Growth and fruit characteristics of Vitis amurensis Rupr., collected in Gangwondo. Korean Journal of Medicinal Crop Science 13(6):226233.

Park YS, Kim IJ,Jeong BC, HeoJY, Park SM (2005b). Pollen characteristics of flower type and cross compatibility with table grape in Vitis amurensis Rupr. Korean Journal of Medicinal CropScience 13(6):234240.

Park YS, Bang SB, Heo JY (2017). A new grape cultivar 'Cheongsan' developed by a cross between genetic resources of Korean native Vitis amurensis Rupr. Vitis 56:197-198.
Purohit S, Nandi S, Paul S, Tariq M, Palni LMS (2017). Micropropagation and genetic fidelity analysis in Amomum subulatum Roxb: a commercially important Himalayan plant. Journal of Applied Research on Medicinal and Aromatic Plants 4:21-26.

Rajoriya P, Singh VK, Lall NJR (2018). Optimizing the effect of plant growth regulators on in vitro micro propagation of Indian red banana (Musa acuminata). Journal of Pharmacognosy and Phytochemistry 8:628-634.

Rani V, Parida A, Raina SN (1995). Random amplified polymorphic DNA (RAPD) markers for genetic analysis in micropropagated plants of Populus deltoides Marsh. Plant Cell Reports 14(7):459-462.

Siddique I, Bukhari NAW, Perveen K, Siddiqui I (2015). Influence of plant growth regulators on in vitro shoot multiplication and plantlet formation in Cassia angustifolia Vahl. Brazilian Archives of Biology and Technology 58(5):686-691.

Sivanesan I, Song JY, Hwang SJ, Jeong BR (2011). Micropropagation of Cotoneaster wilsonii Nakai-a rare endemic ornamental plant. Plant Cell, Tissue and Organ Culture 105(1):55-63.

Skiada FG, Grigoriadou K, Eleftheriou EP (2010). Micropropagation of Vitis vinifera L. cv. 'Malagouzia' and 'Xinomavro'. Central European Journal of Biology 5(6):839-952.

Song RG, Lu RP, Shen YJ, Jin RH, Li XH, Guo ZG, ... Lin XG (2008). A new ice-red brewing grape cultivar 'Beibinghong. Acta Horticulturae Sinica 7:1085.

Toma RS (2018). Micropropagation response of three grape vines (Vitis vinifera $\mathrm{L}$.) cultivars to ferrous, nitrate and growth regulators. VegetosAn International Journal of Plant Research 31(3):126-131.

Yildirim H, Ozdemir G (2018). Influence of BAP concentrations and nutrient medium composition on in vitro regeneration of 'Öküzgözü' and 'Boğazkere' (Vitis vinifera L.) cultivars. Erwerbs-Obstbau 60(1):5559. 